\title{
Porous Carbon Nanosheets Prepared from Plastic Wastes for Supercapacitors
}

\author{
GUOXU WANG,${ }^{1}$ LEI LIU, ${ }^{1}$ LILI ZHANG,${ }^{1}$ XINYU FU, ${ }^{1}$ MENG LIU, ${ }^{1}$ \\ YIXIN ZHANG, ${ }^{1}$ YIFENG YU, ${ }^{1,2}$ and AIBING CHEN ${ }^{1,3}$
}

1.-College of Chemical and Pharmaceutical Engineering, Hebei University of Science and Technology, Shijiazhuang 050018, China. 2.—e-mail: kdyyf@163.com. 3.—e-mail: chen_ab@163.com

With the rise of living standards, non-biodegradable waste, especially waste plastics, has caused serious environmental problems. Herein, we prepare nitrogen doped porous carbon nanosheets (N-PCNs) using magnesium hydroxide $\left[\mathrm{Mg}(\mathrm{OH})_{2}\right]$ sheets, which are modified by $\mathrm{Zn}$ and Co bimetallic zeolitic imidazolate framework nanoparticles as templates and polystyrene (PS) as a carbon precursor. During the high-temperature pyrolysis process, PS pyrolyzes into small organic molecule gases, which can be converted into graphene-like carbon material under the catalyst magnesia $(\mathrm{MgO})$ and $\mathrm{Co}$ species. Nitrogen is introduced into the carbon material in situ by the pyrolysis of imidazole ligands, and the evaporation of $\mathrm{Zn}$ helps increase the surface area. The obtained N-PCNs with porous structure and large specific surface area can be used as electrode material for supercapacitors, exhibiting excellent capacitance of $149 \mathrm{~F} \mathrm{~g}^{-1}$ at the current density of $0.5 \mathrm{~A} \mathrm{~g}^{-1}$, an excellent cycling stability of $97.6 \%$ for up to 5000 cycles.

\section{Graphical Abstract}

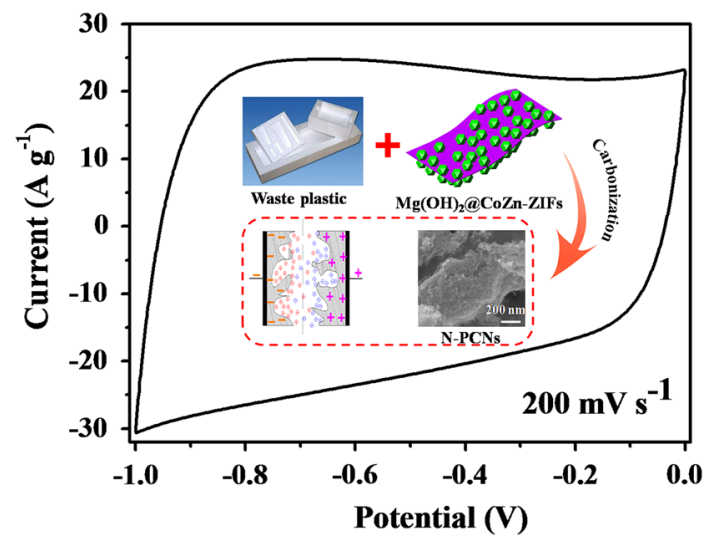

Key words: Polystyrene, $\mathrm{Mg}(\mathrm{OH})_{2}$ sheets, zeolitic imidazolate, porous structure, supercapacitor

(Received December 6, 2017; accepted June 29, 2018; published online July 9, 2018)

\section{INTRODUCTION}

Plastic products are attractive for businesses and consumers because they are light weight, have high strength, are convenient and inexpensive. These plastic products, such as plastic bags, cups, plates 
and packages, while convenient, are also problematic, especially as concerns environmental pollution. Recently, numerous countries have passed legislation to restrict littering waste plastics ${ }^{1,2}$ but the results are not satisfactory. The ever-growing production and consumption of plastic products make environmental problems more serious. How to treat waste plastics has attracted global attention. The common methods nowadays to treat waste plastics are by landfill or incineration, which seem to reduce the spread of waste plastics effectively, but actually cause secondary pollution. Plastics buried in landfills release toxic substances into soil and water, and plastics incinerated produce poisonous gases and carbon dioxide. ${ }^{3,4}$ It is significant for ecological sustainable development and protection of the environment to search for alternative treatments for waste plastics.

In recent years, with the fast-growing demand for computers, mobile phones, electric vehicles and other electric equipment, supercapacitors have attracted increasing attention because of their high specific power and long cycling life. ${ }^{5}$ Porous carbon with specific morphology and heteroatomic doping have been used as effective electrode materials for supercapacitors due to their large surface area, tunable size, high chemical and physical stability, good conductivity and low cost. ${ }^{5-8}$ Waste plastics, including polypropylene (PP), polystyrene (PS), polyethylene (PE), polyvinyl chlorine (PVC), polyethylene terephthalate (PET) and low density polyethylene (LDPE), have aroused the attention of an increasing number of researchers due to their high carbon content. ${ }^{9,10}$ It will mean great progress when we are able to turn the waste plastics into high-value carbon materials in terms of effective utilization of waste resources. Up to now, carbon materials with different morphology have been prepared using waste plastics, such as carbon nanotubes, ${ }^{11}$ carbon spheres,${ }^{12-14}$ graphene, ${ }^{15}$ porous carbon nanosheets (PCNs) ${ }^{16}$ Among of these carbon materials, $\mathrm{PCN}$ s have received considerable attention in the field of energy storage, especially in electrochemical double-layer capacitors (EDLCs), for their sheet-like structure, large specific surface area, porous properties and graphitization. ${ }^{17}$ They show promising use because of their: sheet-like structure that can speed up ion transport and shorten the distance ${ }^{18}$; large specific surface area that can provide abundant electrode/electrolyte interfaces for ion storage and promote rapid charge-transfer reaction ${ }^{19,20}$; macropores work as ion-buffering reservoirs to shorten the distance for ion transport; mesopores provide low-resistant pathways for fast ion transmission ${ }^{21}$; micropores enhance the electrical double layer ${ }^{22}$; and the presence of heteroatoms (such as $\mathrm{N}, \mathrm{O}, \mathrm{S}$ ) improve the electrical conductivity and wettability. ${ }^{23}$ There is no doubt that multiple synergistic effects of the aforementioned properties improve the electrochemical properties of PCNs to the full extent.
Herein, we demonstrate a facile way to prepare nitrogen doped porous carbon nanosheets $(\mathrm{N}$ PCNs). As a common type of waste plastic, PS is selected as the carbon precursor. $\mathrm{Zn}$ and $\mathrm{Co}$ bimetallic zeolitic imidazolate framework (CoZnZIF) nanocrystals grown on magnesium hydroxide $\left[\mathrm{Mg}(\mathrm{OH})_{2}\right]$ sheets function as a template [called $\left.\mathrm{Mg}(\mathrm{OH})_{2} @ \mathrm{CoZn}-\mathrm{ZIFs}\right]$. Under high temperature treatment, $\mathrm{Mg}(\mathrm{OH})_{2}$ converts to magnesia $(\mathrm{MgO})$, which helps to convert the gas-phase carbon precursors derived from PS decomposition into carbon framework. The nitrogen is introduced into the carbon material in situ by means of pyrolysis of imidazole ligands, and the evaporation of $\mathrm{Zn}$ leads to a high surface area. The existence of Co species can catalytically graphitize the carbon material. After removing the templates and Co species, the $\mathrm{N}$ $\mathrm{PCNs}$ with porous structure and large specific surface area are obtained. The N-PCNs as electrodes exhibit a specific capacitance of $149 \mathrm{~F} \mathrm{~g}^{-1}$ at a current density of $0.5 \mathrm{~A} \mathrm{~g}^{-1}$ in $6 \mathrm{M} \mathrm{KOH}$ electrolyte and excellent cycling stability of $97.6 \%$ even after 5000 cycles.

\section{EXPERIMENTAL METHODS}

\section{Preparation of $\mathrm{MgO}$ Rods}

$\mathrm{MgO}$ rods were prepared according to a previous report. ${ }^{24}$ For the specific synthetic process, sodium carbonate $\left(\mathrm{Na}_{2} \mathrm{CO}_{3}\right)$ solution was dropwise added to magnesium chloride $\left(\mathrm{MgCl}_{2}\right)$ solution under continuous stirring $\left(\mathrm{Na}_{2} \mathrm{CO}_{3}\right.$ and $\mathrm{MgCl}_{2}$ with a $1: 1 \mathrm{~mol}$ ratio). The precipitate magnesium carbonate $\left(\mathrm{MgCO}_{3}\right)$ was collected by centrifugation after stirring at room temperature for $4 \mathrm{~h}$. $\mathrm{MgO}$ micorods were obtained by calcining $\mathrm{MgCO}_{3}$ under air atmosphere at $500^{\circ} \mathrm{C}$ for $2 \mathrm{~h}$.

\section{Preparation of $\operatorname{Mg}(\mathrm{OH})_{2}$ and $\mathrm{Mg}(\mathrm{OH})_{2} @ \mathrm{CoZn}$ - ZIFs Sheets}

A $0.2-\mathrm{g}$ sample of $\mathrm{MgO}$ rods reacted with water for $3 \mathrm{~h}$, and then $\mathrm{Mg}(\mathrm{OH})_{2}$ sheets were collected by centrifugation and dried at $60^{\circ} \mathrm{C}$. A $0.32-\mathrm{g}$ sample of the as-prepared $\mathrm{Mg}(\mathrm{OH})_{2}$ sheets and $1.58 \mathrm{~g}$ of PVP was dispersed in $40 \mathrm{~mL}$ methanol by sonication and stirring. Five milliliters of methanol containing $0.14 \mathrm{~g}$ zinc nitrate and $0.09 \mathrm{~g}$ cobalt nitrate was dispersed into the suspension under magnetic stirring for $1 \mathrm{~h}$ at room temperature. After that, the solution containing $0.23 \mathrm{~g}$ 2-methylimidazole (Hmim) and $5 \mathrm{~mL}$ of methanol was added dropwise into the solution under stirring for $15 \mathrm{~min}$. Then the mixed solution was kept for $5 \mathrm{~h}$ at room temperature. Afterwards, the $\mathrm{Mg}(\mathrm{OH})_{2} @ \mathrm{CoZn}$-ZIFs sheets composite was collected by centrifuging and dried in vacuum oven.

\section{Preparation of PCNs and N-PCNs}

A 0.5-g sample of $\mathrm{Mg}(\mathrm{OH})_{2}$ sheets was mixed with $0.5 \mathrm{~g}$ PS following carbonization under $\mathrm{N}_{2}$ 
atmosphere at $900^{\circ} \mathrm{C}$ for $3 \mathrm{~h}$. The PCNs were obtained after removing the templates. N-PCNs were prepared using $\mathrm{Mg}(\mathrm{OH})_{2} @ \mathrm{CoZn}$-ZIFs sheets as a template in a similar preparation to the PCNs. The hard templates and Co species were removed using $4 \mathrm{M}$ hydrochloric acid.

\section{Characterization}

Nitrogen adsorption-desorption isotherms were carried out on a Micromeritics TriStar 3020 volumetric adsorption analyzer at $-196^{\circ} \mathrm{C}$. The Brunauer-Emmett-Teller (BET) method was utilized to calculate the specific surface area of each sample and the Barrett-Joyner-Halenda (BJH) method was used to calculate the average pore size. The total pore volume was estimated from the $\mathrm{N}_{2}$ amount adsorbed at a relative pressure of $P /$ $P_{0}=0.97$. Scanning electron microscopy (SEM) analysis was conducted using a HITACHI S-4800-I scanning electron microscope. Transmission electron micrographs (TEM) were obtained on a JEOL JEM-2100 electron microscope. X-ray photoelectron spectrometer (XPS) data were collected by using an AXIS ULTRA DLD spectrometer with Al K $\alpha$ radiation as the excitation source. Powder X-ray diffraction (XRD) patterns were carried out on a Rigaku D/ MAX-2500 diffractometer using $\mathrm{Cu} \mathrm{K} \alpha$ radiation.

\section{Electrochemical Measurements}

The working electrodes were prepared by coating active material, carbon black and $60 \mathrm{wt} . \%$ polytetrafluoroethylene with mass ratio 8:1:1 in a small amount of ethanol on $\mathrm{Ni}$ foam substrate. Subsequently, the electrodes were dried at $100^{\circ} \mathrm{C}$ for $24 \mathrm{~h}$. The measurements were measured in a threeelectrode system on an electrochemical working station (CHI 760E) in $6 \mathrm{M} \mathrm{KOH}$ electrolyte at room temperature. The $\mathrm{Hg} / \mathrm{HgO}$ electrode and platinum wire served as the reference electrode and counter electrode, respectively. All electrochemical behaviors of the working electrodes were tested by cyclic voltammetry (CV), galvanostatic charge-discharge (GCD), electrical impedance spectroscopy (EIS) and cycling stability. The voltage for $\mathrm{CV}$ and GCD ranged from $-1 \mathrm{~V}$ to $0 \mathrm{~V}$. The scan rates of the $\mathrm{CV}$ were from $5 \mathrm{mV} \mathrm{s}^{-1}$ to $200 \mathrm{mV} \mathrm{s}^{-1}$ and the current densities of the GCD were from $0.5 \mathrm{~A} \mathrm{~g}^{-}$to $10 \mathrm{~A} \mathrm{~g}^{-1}$.

\section{RESULTS AND DISCUSSION}

The route for preparing PCNs and N-PCNs is presented in Scheme 1. First, the as-prepared $\mathrm{Mg}(\mathrm{OH})_{2}$ sheets are used as the hard templates for preparing PCNs and N-PCNs. PCNs are prepared by carbonizing the mixture of $\mathrm{Mg}(\mathrm{OH})_{2}$ sheets and PS directly. During the high temperature treatment, $\mathrm{Mg}(\mathrm{OH})_{2}$ transformed to $\mathrm{MgO}$ and simultaneously various carbon-containing small molecule gases released from PS converted into carbon

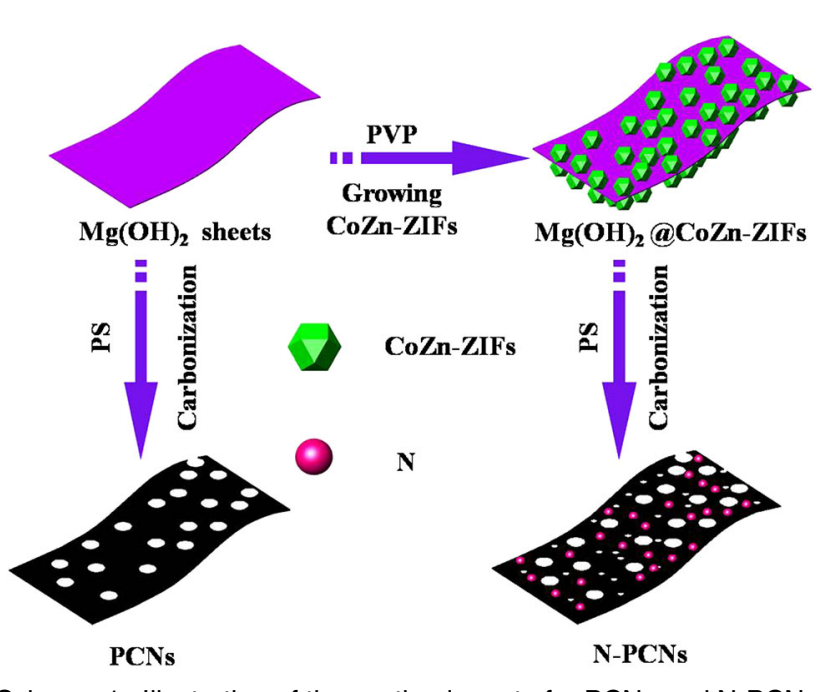

Scheme 1. Illustration of the synthesis route for PCNs and N-PCNs.

framework under the catalysis of $\mathrm{MgO}$. Then, the $\mathrm{PCNs}$ are obtained after removing the templates. In order to improve the physical and electrochemical properties of PCNs further, the templates of $\mathrm{Mg}(\mathrm{OH})_{2}$ sheets are modified by CoZn-ZIFs nanocrystals for preparation of N-PCNs. In this process, the surface of $\mathrm{Mg}(\mathrm{OH})_{2}$ sheets are functionalized with PVP molecules by thorough ultrasonic treatment. The amide carbonyl groups of PVP can be coordinated with Co and $\mathrm{Zn}$ ions ${ }^{25,26}$ which promote the growth of CoZn-ZIF crystals on $\mathrm{Mg}(\mathrm{OH})_{2}$ sheets and the product termed $\mathrm{Mg}(\mathrm{OH})_{2} @$ CoZn-ZIFs. When the mixture of $\mathrm{Mg}(\mathrm{OH})_{2} @ \mathrm{CoZn}$ ZIFs and PS is heated to $900^{\circ} \mathrm{C}, \mathrm{Zn}$ element evaporates to generate more micro- or mesopores in the N-PCNs ${ }^{25,27}$ and Co species work as catalysts to promote the degree of graphitization of N-PCNs. Furthermore, nitrogen is introduced into the carbon framework of N-PCNs through pyrolysis of imidazole ligands. ${ }^{28}$ After etching the templates and Co species, the N-PCNs are obtained.

The morphology of $\mathrm{Mg}(\mathrm{OH})_{2}$ sheets, PCNs, $\mathrm{Mg}(\mathrm{OH})_{2} @ \mathrm{CoZn}-\mathrm{ZIF}$ s and N-PCNs are investigated by SEM images. As shown in Fig. 1a, the $\mathrm{Mg}(\mathrm{OH})_{2}$ sheets with smooth surface and thickness of about 10-20 nm (inset in Fig. 1a) can be observed, which are ideal templates for synthesis of sheet-like structure carbon materials. Their sizes range from several hundreds of nanometers to $\sim 2 \mu \mathrm{m}$. During the carbonization, $\mathrm{Mg}(\mathrm{OH})_{2}$ evolves into $\mathrm{MgO}$. Then $\mathrm{MgO}$ works as an effective catalyst for conversion of organic gases, which derive from the decomposition of PS into carbon materials. ${ }^{29,30}$ After removing templates, the PCNs can be obtained, as shown in Fig. 1b. The image confirms that the sheet-like feature is well preserved. As can be seen, PCNs with irregular bulk morphology are several hundred nanometers to $\sim 2 \mu \mathrm{m}$ in width. With growth of CoZn-ZIFs, numerous nanoparticles (Fig. 1c) with a size of about 50 to $100 \mathrm{~nm}$ are distributed uniformly 

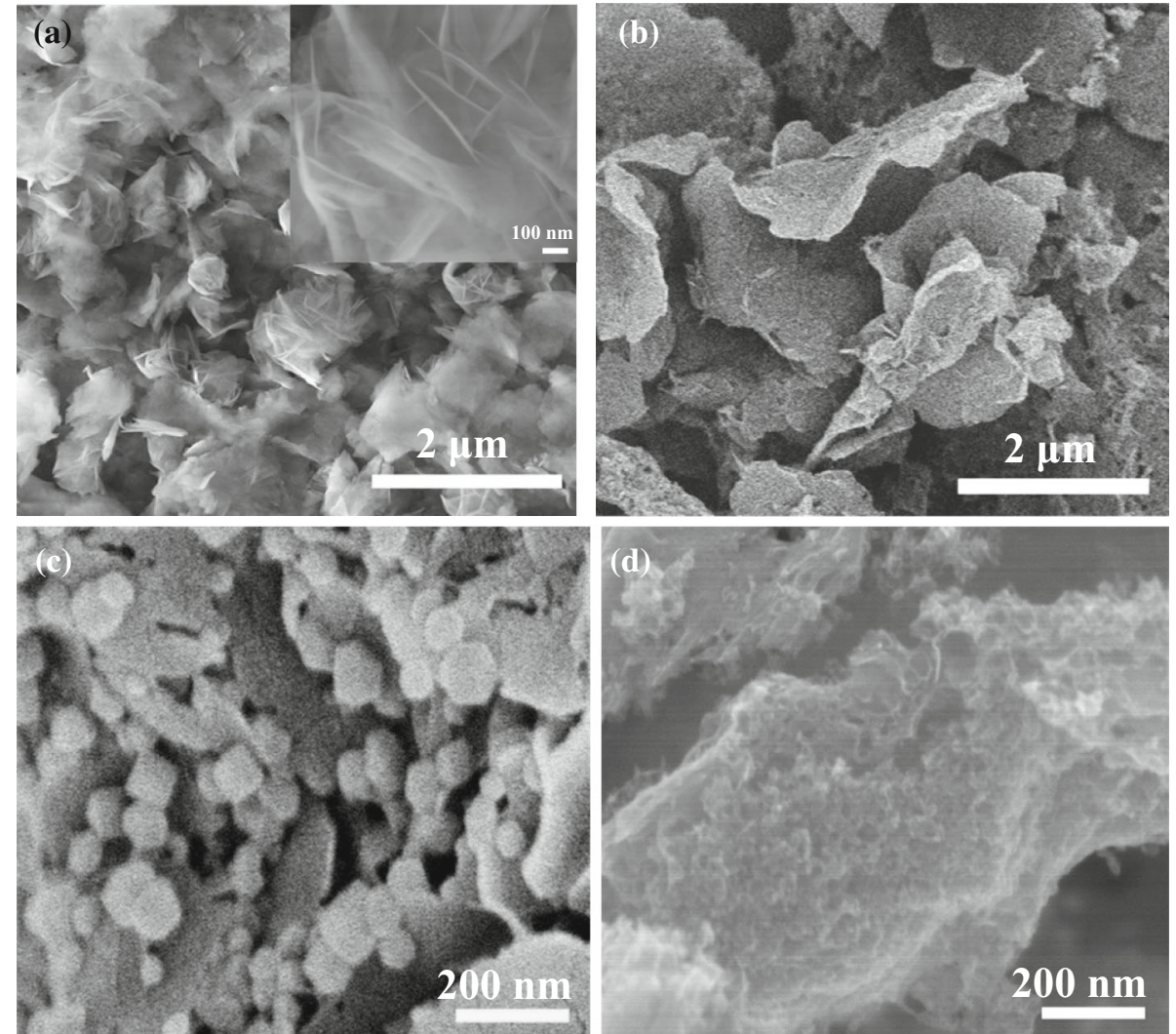

Fig. 1. SEM images of (a) $\mathrm{Mg}(\mathrm{OH})_{2}$ sheets, (b) PCNs, (c) $\mathrm{Mg}(\mathrm{OH})_{2} @ \mathrm{CoZn-ZIFs,} \mathrm{and} \mathrm{(d)} \mathrm{N-PCNs.}$

on the $\mathrm{Mg}(\mathrm{OH})_{2}$ sheets, suggesting that CoZn-ZIF crystals are successfully grown on the surface of $\mathrm{Mg}(\mathrm{OH})_{2}$, forming the composite of $\mathrm{Mg}(\mathrm{OH})_{2} @ \mathrm{CoZn}$ ZIF. Figure 1d shows that the sheet-like morphology of N-PCNs is well preserved after carbonization the mixture of $\mathrm{Mg}(\mathrm{OH})_{2} @ \mathrm{CoZn}-\mathrm{ZIF}$ and PS. Moreover, the N-PCNs exhibit very rough surface and abundant macropores. These macropores can act as ion-buffering reservoirs in the application of electric double-layer capacitors (EDLCs) and benefit for quick and effective ion transport.

The wide-angle XRD patterns are also measured to demonstrate formation of CoZn-ZIFs nanoparticles on the surface of $\mathrm{Mg}(\mathrm{OH})_{2}$ sheets and graphitization degree of PCNs and N-PCNs. Figure 2a shows that the characteristic peaks at $2 \theta=7.4^{\circ}$, $10.5^{\circ}, 12.5^{\circ}, 14.6^{\circ}, 16.5^{\circ}, 24.7^{\circ}$ and $29.8^{\circ}$ observed in the XRD patterns are in good agreement with the standard ZIF-67/8 $8^{31,32}$ while the peaks $2 \theta=18.6^{\circ}$, $38.0^{\circ}, 50.9^{\circ}, 58.9^{\circ}$ and $62.0^{\circ}$ can be assigned to $\mathrm{Mg}(\mathrm{OH})_{2}$. This result further confirms that the CoZn-ZIFs nanoparticles successfully grow on the surface of $\mathrm{Mg}(\mathrm{OH})_{2}$ sheets. In Fig. 2b, two broad diffraction peaks of N-PCNs at $2 \theta=25.3^{\circ}$ and $43^{\circ}$ corresponding to the typical (002) and (100) planes of graphitic carbon materials are observed, ${ }^{33}$ which are both sharper than that of PCNs, suggesting that $\mathrm{N}-\mathrm{PCNs}$ have a higher degree of graphitization (Fig. 2b).
The TEM images are investigated in order to obtain the detailed morphology of PCNs and $\mathrm{N}$ PCNs. From the low magnification TEM image (Fig. 3a), PCNs exhibit a crumbled and wrinkle-rich sheet-like morphology, which corresponds well with the results of SEM. In the high magnification in the Fig. 3b, the PCNs composed of mainly disordered, amorphous carbon can be observed. The N-PCNs (Fig. 3c) display interconnected framework with stacking structure and numerous macropores (dashed circles in Fig. 3c) on the nanosheets. High magnification TEM image Fig. $3 d$ shows that NPCNs have highly graphitic carbon and obviously lattice fringes, whose interplanar distance is measured to be $0.36 \mathrm{~nm}$, which is slightly larger than that of bulk graphite $(0.335 \mathrm{~nm})$. The result may be attributed to the folding of the N-PCNs in different parts increasing the stress in them. ${ }^{34}$ Highly graphitic structure can enhance the electric conductivity of N-PCNs.

To investigate the texture properties of $\mathrm{PCNs}$ and $\mathrm{N}-\mathrm{PCNs}$ further, nitrogen adsorption/desorption isotherms are measured, as shown in Fig. 4a. The PCNs and N-PCNs both exhibit the type IV isotherms. Moreover, their adsorption/desorption isotherms have obvious hysteresis loops at a relative pressure $0.4-1.0 P / P_{0}$, suggesting that they possess mesopores. Furthermore, they have a sharp capillary condensation step at relative high pressures 

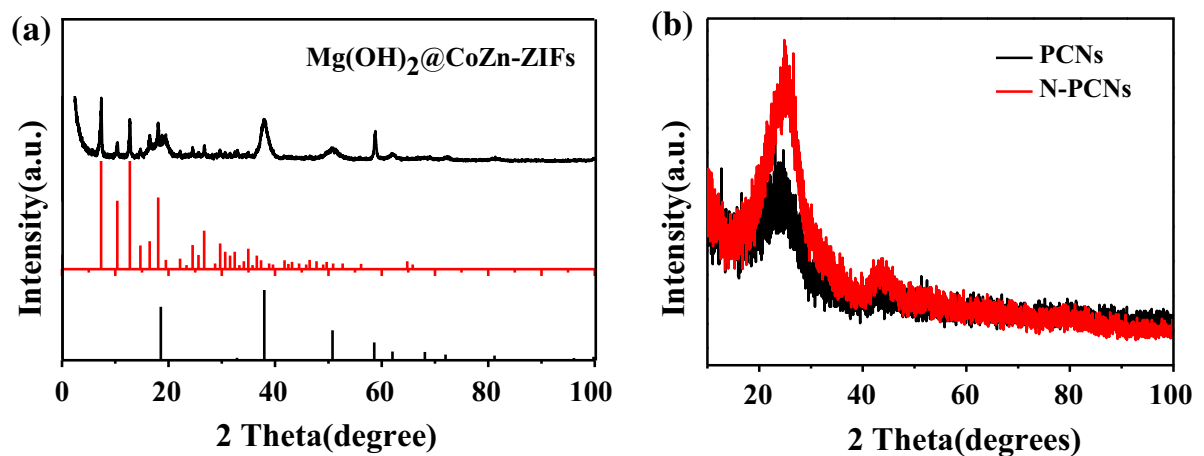

Fig. 2. Corresponding wide angle XRD patterns of the (a) Mg(OH) $)_{2} @ \mathrm{CoZn}-\mathrm{ZIFs}$ and (b) PCNs and N-PCNs.
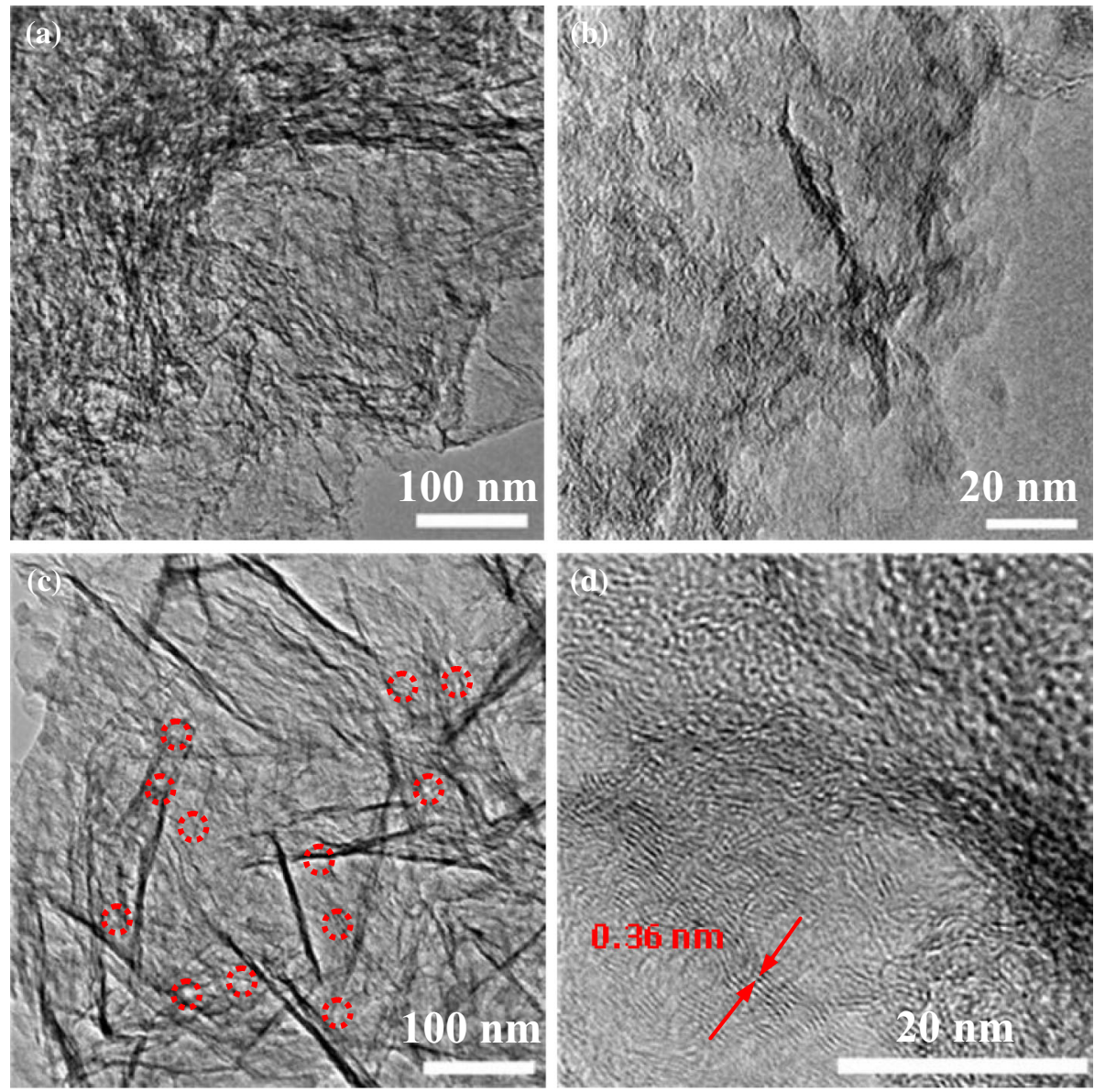

Fig. 3. TEM images of $(a, b) P C N s$ and $(c, d) N-P C N s$ at different magnification.

suggesting the presence of larger pores. ${ }^{17}$ Compared with PCNs, N-PCNs possess larger surface area and pore volume. The specific surface area of PCNs and $\mathrm{N}-\mathrm{PCNs}$ are $804 \mathrm{~m}^{2} \mathrm{~g}^{-1}$ and $1051 \mathrm{~m}^{2} \mathrm{~g}^{-1}$, respectively. The total pore volumes are $2.50 \mathrm{~m}^{3} \mathrm{~g}^{-1}$ and $2.58 \mathrm{~m}^{3} \mathrm{~g}^{-1}$, respectively. The corresponding pore size distribution curves of PCNs and N-PCNs are displayed in Fig. 4b, which are calculated from the adsorption branches by BJH method. The PCNs pore size distribution center at $30.0 \mathrm{~nm}$ and the $\mathrm{N}$ PCNs pore size distribution center at $7.7 \mathrm{~nm}$ and
$45.0 \mathrm{~nm}$. The results suggest that the CoZn-ZIFs nanoparticles create more pores and improve the surface area of N-PCNs during the heat treatment, which further facilitate ion transport and storage.

To explore the composition and functional groups of the N-PCNs, XPS measurements are performed. The result reveals that $\mathrm{N}-\mathrm{PCNs}$ consist of $\mathrm{C}$ (93.52 wt.\%), $\mathrm{N}(2.47$ wt.\%) and $\mathrm{O}$ (4.01 wt.\%), and there are no $\mathrm{Mg}$, Co and $\mathrm{Zn}$ signals, indicating complete removal of these elements (Fig. 5a). The XPS survey spectrum shows a predominant narrow 

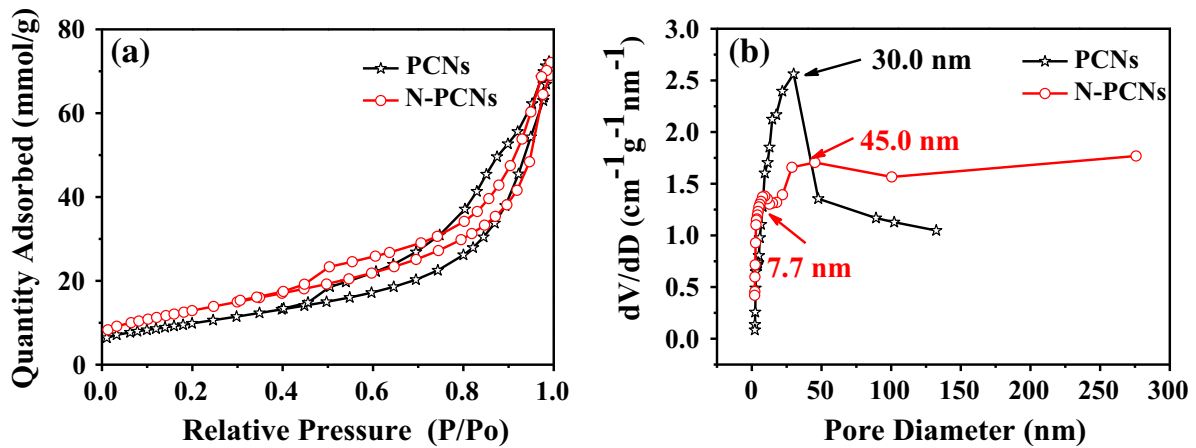

Fig. 4. (a) Nitrogen adsorption-desorption isotherms, and the (b) pore size distributions of PCNs and N-PCNs.

graphitic $\mathrm{C} 1 \mathrm{~s}$ peak at $284.8 \mathrm{eV}, \mathrm{N} 1 \mathrm{~s}$ peak at $400.8 \mathrm{eV}$ and $\mathrm{O} 1 \mathrm{~s}$ peak at $532.8 \mathrm{eV}$. The high resolution of the $\mathrm{C} 1 \mathrm{~s}$ spectrum (Fig. $5 \mathrm{~b}$ ) can be deconvoluted to four peaks, corresponding to $\mathrm{C}=\mathrm{C}$ $(284.6 \mathrm{eV}), \mathrm{C}-\mathrm{N}(285.4 \mathrm{eV}), \mathrm{C}-\mathrm{O}(286.7 \mathrm{eV})$ and $\mathrm{O}-$ $\mathrm{C}=\mathrm{O}(289.9 \mathrm{eV})$ functional groups. ${ }^{35}$ The spectrum of N1s (Fig. 5c) can be fitted into three peaks with bonding energy at $398.5 \mathrm{eV}, 401.1 \mathrm{eV}$ and $403.2 \mathrm{eV}$ attributable to the pyridinic- $\mathrm{N}$, quaternary-N and oxidized-N, respectively. ${ }^{36,37}$ The quaternary-N is the most stable nitrogen species during the process of pyrolysis, which can improve the electrical conductivity of the carbon materials. ${ }^{36}$ The inset of Fig. 5c shows three doping nitrogen forms in the $\mathrm{N}$ PCNs. The spectrum of O1s (Fig. 5d) can be deconvoluted into two peaks at $531.0 \mathrm{eV}$ and $532.8 \mathrm{eV}$ that correspond to quinine and $\mathrm{C}=\mathrm{O} \cdot{ }^{35,38}$

Based on the aforementioned characteristics, including sheet-like morphology, nitrogen doped nature, high specific surface area and porous structure, the N-PCNs are potentials for supercapacitor applications. The electrochemical properties are investigated in a $6 \mathrm{M} \mathrm{KOH}$ aqueous solution by CV, GCD and Nyquist plots within the potential window of $-1 \mathrm{~V}$ to $0 \mathrm{~V}$ in a three-electrode system. For comparison, the sample of PCNs is also measured in the same system. As shown in Fig. 6a, $\mathrm{PCNs}$ and N-PCNs both retain a nearly quasirectangular shape even at a scan rate of $200 \mathrm{mV} \mathrm{s}^{-1}$. However, N-PCNs possess a larger integrated area than PCNs, suggesting that the capacitance of N-PCNs is larger than that of PCNs. In order to investigate their electrochemical properties further, GCD is measured at a current density of $0.5 \mathrm{~A} \mathrm{~g}^{-1}$. As shown in Fig. $6 \mathrm{~b}$, the sample of N-PCNs has longer discharge time than that of PCNs, which means that N-PCNs have larger capacitance. The corresponding specific capacitances of PCNs and N-PCNs calculated based on the GCD at different current densities are presented in Fig. 6c. The capacitances of PCNs and N-PCNs electrodes are $93.1 \mathrm{~F} \mathrm{~g} \mathrm{~g}^{-1}$ and $149 \mathrm{~F} \mathrm{~g}^{-1}$ at $0.5 \mathrm{~A} \mathrm{~g}^{-1}$ and remains at $77 \mathrm{~F} \mathrm{~g}^{-1}$ and $118 \mathrm{~F} \mathrm{~g}^{-1}$ at $10 \mathrm{~A} \mathrm{~g}^{-1}$ with a capacitance retention of $79.2 \%$ and $82.7 \%$, respectively. Obviously, the specific capacitance of N-PCNs at different current densities is higher than that of PCNs, which may because N-PCNs have larger surface area, are nitrogen doped and have a higher degree of graphitization. Nyquist plots of PCNs and NPCNs are shown in Fig. 6d. As can be seen from the high frequency region of the Nyquist plots (inset in Fig. 6d), they both exhibit low interfacial connection resistance and almost steep liner curves at low frequency, owing to their sheet-like structure and abundant and accessible pores.

As shown in Fig. 7a, the CV curves at scan rates from $5 \mathrm{mV} \mathrm{s}^{-1}$ to $200 \mathrm{mV} \mathrm{s}^{-1}$ demonstrate an almost quasi-rectangular shape without obvious distortion, indicating its ideal capacitive behavior and good reversibility. ${ }^{39,40}$ Figure $7 \mathrm{~b}$ shows the GCD curves of N-PCNs at the different current densities from $0.5 \mathrm{~A} \mathrm{~g}^{-1}$ to $10 \mathrm{~A} \mathrm{~g}^{-1}$, which exhibit highly symmetrical isosceles triangular shapes at various current densities, suggesting an ideal EDLC behavior and superior electrochemical reversibility. The long-time cycling stability of the material is another important factor to identify the feasibility for practical application of supercapacitors. After testing N-PCNs for 5000 GCD cycles at a current density of $5 \mathrm{~A} \mathrm{~g}^{-1}$, N-PCNs still maintain $97.6 \%$ of the initial capacitance (Fig. 7c), indicating its excellent cycling stability and good application prospect in the field of EDLCs. Figure 7d shows the schematic of EDLCs when N-PCNs work as an electrode material. N-PCNs with special sheet-like structure, high specific surface area, porous structure, graphitization and heteroatom doped for electrochemical supercapacitors should have the advantages as follows: (1) 2D sheet-like structure can speed up ion transport and shorten the transport length of ions; (2) the abundant wrinkled structures can 

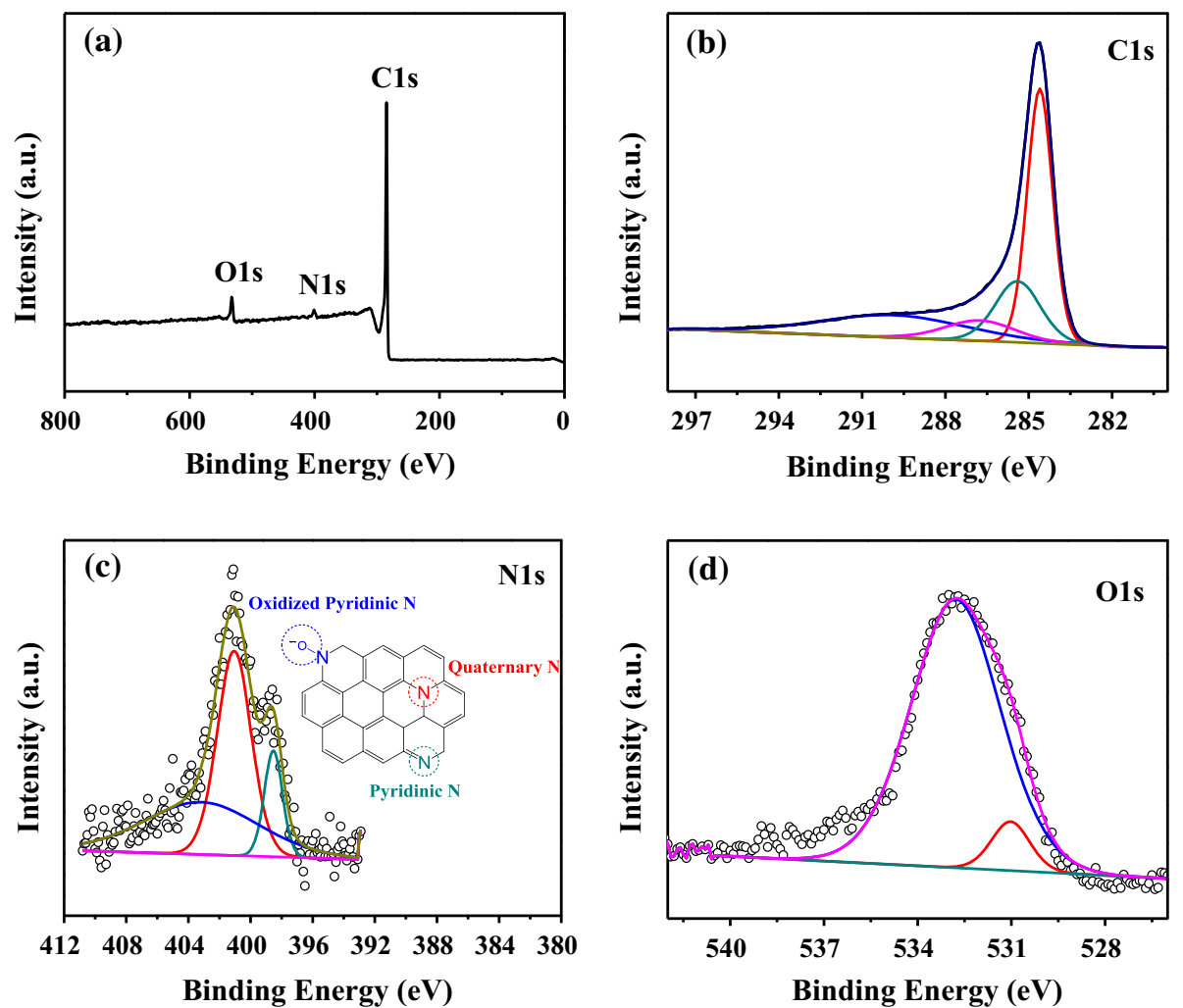

Fig. 5. (a) XPS spectrum, (b) C1s spectrum, (c) N1s spectrum, and (d) O1s spectrum of N-PCNs.
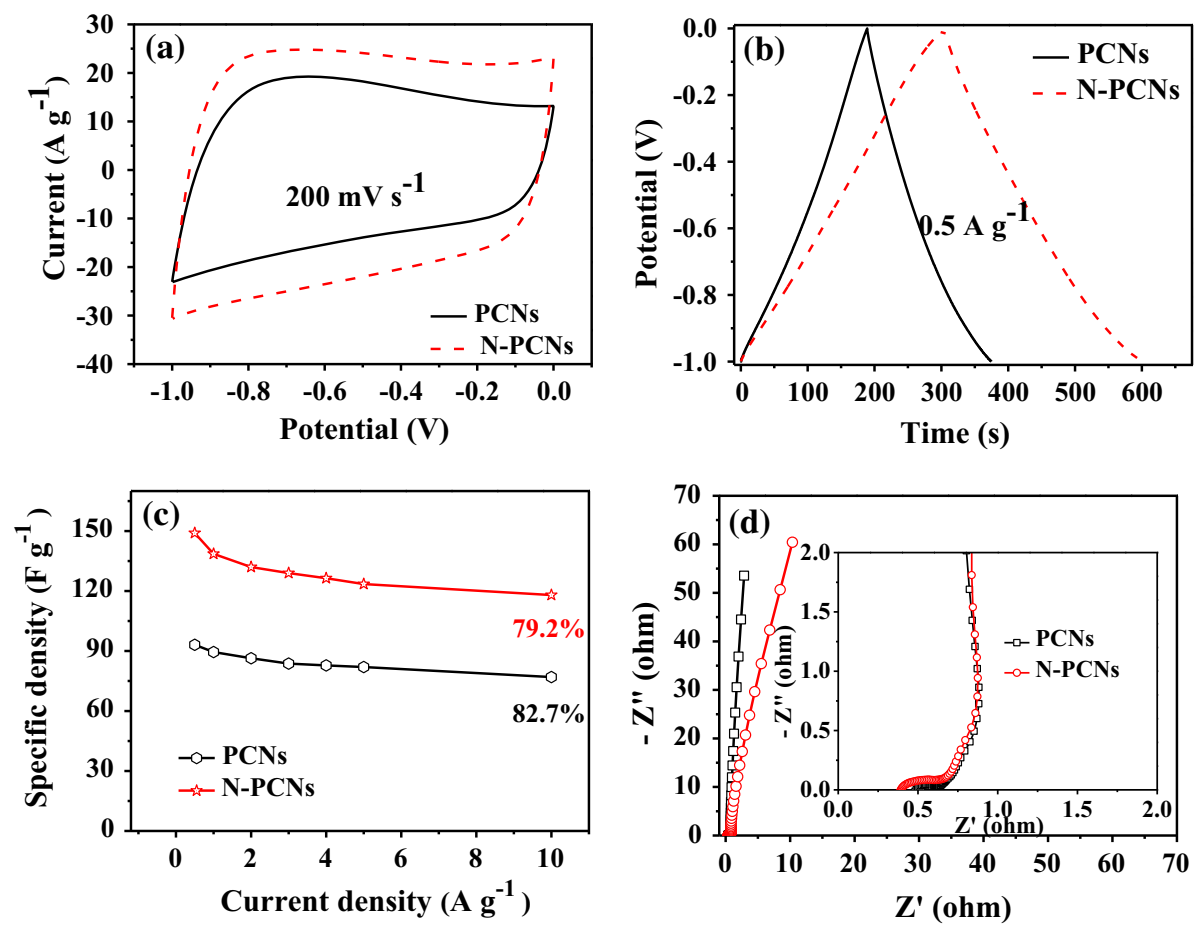

Fig. 6. Electrochemical measurements of PCNs and N-PCNs. (a) CV curves at scan rate of $200 \mathrm{mV} \mathrm{s}^{-1}$. (b) GCD curves at current density of $0.5 \mathrm{~A} \mathrm{~g}^{-1}$. (c) Specific capacitances at different current densities. (d) Nyquist plots measured with frequency range of $10^{5}-10^{-2} \mathrm{~Hz}$. The inset in (d) shows the corresponding magnified high-frequency regions. 

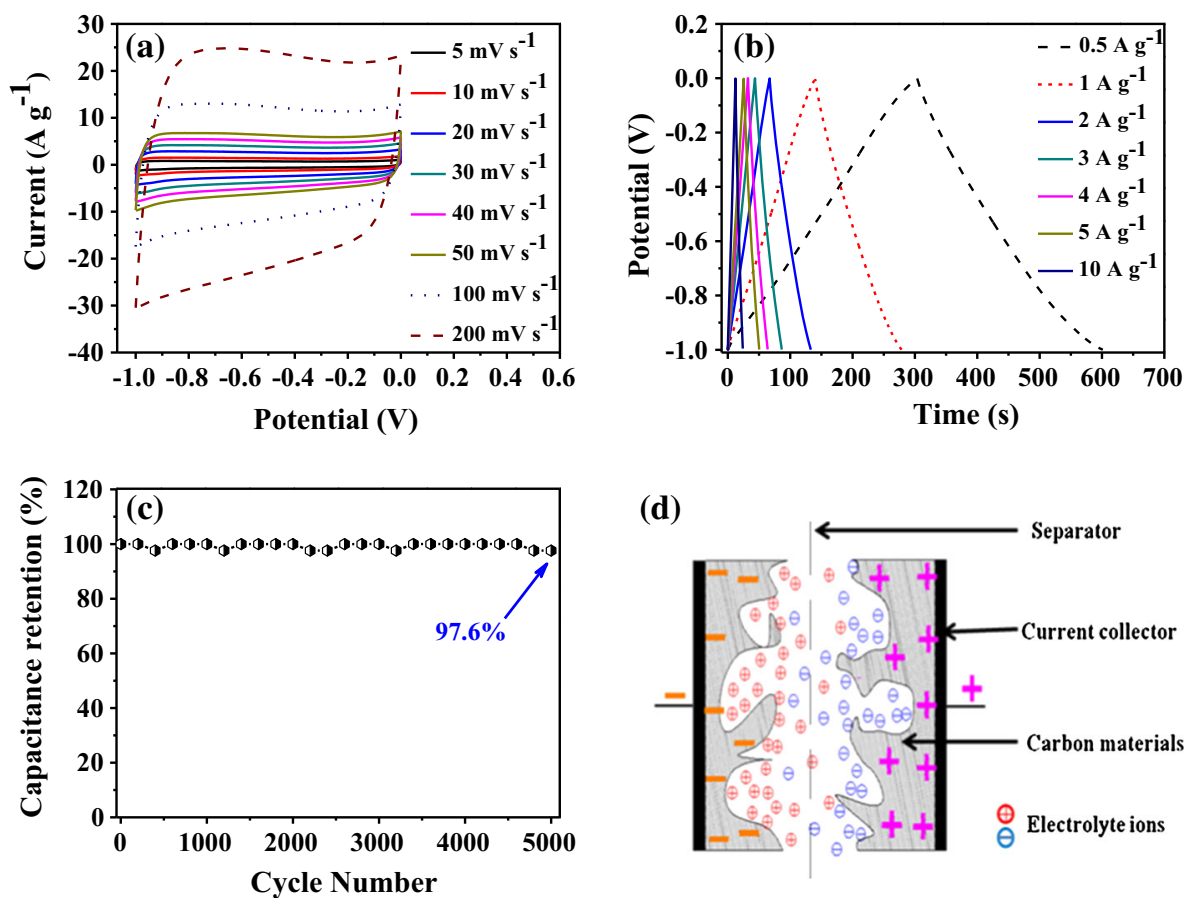

Fig. 7. (a) CV curves of N-PCNs at different scan rates from $5 \mathrm{mV} \mathrm{s}^{-1}$ to $200 \mathrm{mV} \mathrm{s}^{-1}$. (b) GCD curves of N-PCNs at different current densities from $0.5 \mathrm{~A} \mathrm{~g}^{-1}$ to $10 \mathrm{~A} \mathrm{~g}^{-1}$. (c) Cycling life of N-PCN electrodes at $5 \mathrm{~A} \mathrm{~g}^{-1}$. (d) Schematic of the porous structure for ion transmission.

provide a large accessible surface area for ion storage; (3) the high specific surface area associating with meso-/macropores provide more active sites and further improve electrical conductivity.

\section{CONCLUSIONS}

In summary, we have reported a feasible approach for preparation of high-value porous carbon nanosheets from PS waste plastics. The obtained N-PCNs possess porous structure, large specific surface area $\left(1051 \mathrm{~m}^{2} \mathrm{~g}^{-1}\right)$ and are nitrogen doped (2.47 wt.\%), resulting in the appropriate specific capacitance $\left(149 \mathrm{~F} \mathrm{~g}^{-1}\right.$ at $\left.0.5 \mathrm{~A} \mathrm{~g}^{-1}\right)$, excellent rate capability (retain $118 \mathrm{~F} \mathrm{~g}^{-1}$ even at $\left.10 \mathrm{~A} \mathrm{~g}^{-1}\right)$ and prominent cycle stability $(97.6 \%$ capacitance retention after 5000 charge-discharge cycles). This research provides an efficient way using of waste plastics for preparation of high value carbon materials and offers a method for reducing the environment stresses resulting from the waste plastics.

\section{ACKNOWLEDGEMENTS}

This work was financially supported by the National Natural Science Foundation of China (21676070), Hebei Natural Science Foundation (B2015208109), Hebei Training Program for Talent Project (A201500117), Five Platform Open Fund Projects of Hebei University of Science and Technology (2015PT37), Hebei One Hundred-Excellent Innovative Talent Program(III) (SLRC2017034), Hebei Science and Technology Project (17214304D,
16214510D), The Excellent Going Abroad Experts' Training Program in Hebei Province.

\section{CONFLICT OF INTEREST}

The authors declare that they have no conflict of interest.

\section{REFERENCES}

1. D. Xanthos and T.R. Walker, Mar. Pollut. Bull. 118, 17 (2017).

2. L. Milios, L.H. Christensen, D. McKinnon, C. Christensen, M.K. Raschb, and M.H. Eriksen, Waste Manag (2018). https://doi.org/10.1016/j.wasman.2018.03.034.

3. C.W. Zhou and Y.A. Levendis, J. Appl. Polym. Sci. 131, 1001 (2014).

4. W.S. Fonseca, X.H. Meng, and D. Deng, ACS Sustain. Chem. Eng. 3, 2153 (2015).

5. C.L. Long, X. Chen, L.L. Jiang, L.J. Zhi, and Z.J. Fan, Nano Energy 12, 141 (2015).

6. J.H. Hou, T. Cao, F. Idrees, and C. Cao, Nanoscale 8, 451 (2016).

7. B. You, J.H. Jiang, S.J. Fan, and A.C.S. Appl, Mater. Interfaces 6, 15302 (2014).

8. J.H. Hou, C.B. Cao, F. Idrees, and X. Ma, ACS Nano 9, 2556 (2015).

9. J. Gong, J. Liu, Z.W. Jiang, X.C. Chen, X. Wen, E. Mijowska, and T. Tang, Appl. Catal. B 152-153, 289 (2014).

10. A. Bazargan, Y. Yan, D.C.W. Hui, and G. McKay, Ind. Eng. Chem. Res. 52, 12689 (2013).

11. J.H. Zhang, L.M. Zhang, H. Yang, Q.H. Kong, Y.H. Liu, and A.H. Yuan, CrystEngComm 16, 8832 (2014).

12. J. Gong, J. Liu, X.C. Chen, X. Wen, Z.W. Jiang, E. Mijowska, Y.H. Wang, and T. Tang, Microporous Mesoporous Mater. 176, 31 (2013).

13. H.B. Hu, L. Gao, C.L. Chen, and Q.W. Chen, Environ. Sci. Technol. 48, 2928 (2014).

14. V.G. Pol, Environ. Sci. Technol. 44, 4753 (2010). 
15. S. Sharma, G. Kalita, R. Hirano, S.M. Shinde, R. Papon, H. Ohtani, and M. Tanemura, Carbon 72, 66 (2014).

16. J. Gong, J. Liu, X.C. Chen, Z.W. Jiang, X. Wen, E. Mijowskac, and T. Tang, J. Mater. Chem. A 3, 341 (2015).

17. H. Peng, G.F. Ma, K.J. Sun, Z.G. Zhang, Q. Yang, and Z.Q. Lei, Electrochim. Acta 190, 862 (2016).

18. N. Wang, C.X. Wu, J.X. Li, G.F. Dong, L.H. Guan, and A.C.S. Appl, Mater. Interfaces 3, 4185 (2011).

19. L. Qie, W.M. Chen, Z.H. Wang, Q.G. Shao, X. Li, L.X. Yuan, X.L. Hu, W.X. Zhang, and Y.H. Huang, Adv. Mater. 24, 2047 (2012).

20. L. Qie, W.M. Chen, H.H. Xu, X.Q. Xiong, Y. Jiang, F. Zou, X.L. Hu, Y. Xin, Z.L. Zhang, and Y.H. Huang, Energy Environ. Sci. 6, 2497 (2013).

21. Y.Y. Li, Z.S. Li, and P.K. Shen, Adv. Mater. 25, 2474 (2013).

22. F. Xu, R.J. Cai, Q.C. Zeng, C. Zou, D. Wu, F. Li, X. Lu, Y. Liang, and R.W. Fu, J. Mater. Chem. 21, 1970 (2011).

23. L. Wan, J.L. Wang, L.J. Xie, Y.H. Sun, K.X. Li, and A.C.S. Appl, Mater. Interfaces 6, 15583 (2014).

24. Z.M. Zheng, X. Zhang, F. Pei, Y. Dai, X.L. Fang, T.H. Wang, and N.F. Zheng, J. Mater. Chem. A 3, 19800 (2015).

25. Z.Q. Xie, Z.Y. He, X.H. Feng, W.W. Xu, X.D. Cui, J.H. Zhang, C. Yan, M.A. Carreon, Z. Liu, Y. Wang, and A.C.S. Appl, Mater. Interfaces 8, 10324 (2016).

26. Z.Q. Li and L.W. Yin, J. Mater. Chem. A 3, 21569 (2015).

27. T. Chen, B.R. Cheng, G.Y. Zhu, R.P. Chen, Y. Hu, L.B. Ma, H.L. Lv, Y.R. Wang, J. Liang, Z.X. Tie, Z. Jin, and J. Liu, Nano Lett. 17, 437 (2017).
28. T. Chen, B.R. Cheng, G.Y. Zhu, R.P. Chen, Y. Hu, L.B. Ma, H.L. Lv, Y.R. Wang, J. Liang, Z.X. Tie, Z. Jin, J. Liu, and A.C.S. Appl, Mater. Interfaces 8, 26834 (2016).

29. Y.L. Wen, J. Liu, J.F. Song, J. Gong, H. Chen, and T. Tang, RSC Adv. 5, 105047 (2015).

30. H.J. Wang, X.X. Sun, Z.H. Liu, and Z.B. Lei, Nanoscale 6, 6577 (2014).

31. A.F. Gross, E. Sherman, and J.J. Vajo, Dalton Trans. 41, 5458 (2012).

32. H. Li, Y. Su, W.W. Sun, and Y. Wang, Adv. Funct. Mater. 26, 8345 (2016).

33. L. Liu, H.L. Zhang, G.X. Wang, J. Du, Y.T. Zhang, X.Y. Fu, and A.B. Chen, J. Mater. Sci. 52, 9640 (2017).

34. K. Qin, Y.X. Su, J.Y. Zhi, H.Z. Xian, X.X. Zhao, B.H. Rong, and S.Z. Lan, Carbon 42, 1737 (2004).

35. J. Wang, H.Y. Liu, J.Y. Diao, X.M. Gu, H.H. Wang, J.F. Rong, B.N. Zong, and D.S. Su, J. Mater. Chem. A 3, 2305 (2015).

36. J.P. Han, G.Y. Xu, B. Ding, J. Pan, H. Dou, and D.R. MacFarlane, J. Mater. Chem. A 2, 5352 (2014).

37. X.Q. Wang, C.G. Liu, D. Neff, P.F. Fulvio, R.T. Mayes, A. Zhamun, Q. Fang, G.R. Chen, H.M. Meyer, B.Z. Jang, and S. Dai, J. Mater. Chem. A 1, 7920 (2013).

38. X.C. Zhao, Q. Zhang, B.S. Zhang, C.M. Chen, A.Q. Wang, T. Zhang, and D.S. Su, J. Mater. Chem. 22, 4963 (2012).

39. Z.J. Fan, Y. Liu, J. Yan, G.Q. Ning, Q. Wang, T. Wei, L.J. Zhi, and F. Wei, Adv. Energy Mater. 2, 419 (2012).

40. M. Sevilla and A.B. Fuertes, ACS Nano 8, 5069 (2014). 